\title{
A Validation of the Hospital Anxiety and Depression Scale (HADS) in the Medically-Ill
}

\author{
Ma. Lourdes Rosanna E. de Guzman \\ Department of Psychiatry and Behavioral Medicine, College of Medicine and Philippine General Hospital, University of the Philippines Manila
}

\begin{abstract}
The underdiagnosis of depression and anxiety in the medically ill warrants attention considering that diagnosis and treatment will definitely improve the quality of life, reduce the risk of medical complications, improve compliance to treatment, provide a better outcome of medical treatment, and facilitate the "appropriate" use of health care resources.
\end{abstract}

Objectives. To determine the prevalence of depression and/or anxiety in the in-patient medically ill and to validate the Hospital Anxiety and Depression Scale (HADS) for Filipinos.

Methods. To aid clinicians, the Hospital Anxiety and Depression Scale (HADS), a 14-item self-report questionnaire was validated in this cross-sectional study of 710 medically ill in-patients, to be able to determine how well it identified depression and anxiety against the criterion of a diagnostic psychiatric interview and to determine the optimal cut-off score of the HADS for Filipinos with the use of the Receiver Operating Characteristics (ROC).

Results. The prevalence of depression was $26.9 \%$, anxiety was $14.3 \%$, and the 'mixed diagnosis' of both was $13.7 \%$ among the medically-ill. The overall prevalence was $54.9 \%$. The results showed that the optimal cut-off score for the HADS/ HADS-P is a score of 11 , with a sensitivity of $75 \%$, specificity of $70 \%$ and PPV of $75 \%$.

Conclusion. The HADS/ HADS-P will provide clinicians with a reliable, valid and practical screening tool for identifying the two most common clinical problems in the medically ill, depression and anxiety. The HADS/HADS-P can serve as a guide for clinicians towards the diagnosis of depression and anxiety, but it cannot be the sole basis for diagnosis.

Key Words: HADS, depression, anxiety

Presented at the 25th Faculty Research Forum, March 17, 2011, College of Medicine, Alvior Hall, UP Manila.

Corresponding author: Ma. Lourdes Rosanna E. de Guzman, MD, MS Epi (Public Health)

Department of Psychiatry and Behavioral Medicine

Philippine General Hospital

University of the Philippines Manila

Taft Avenue, Ermita, Manila 1000 Philippines

Telephone: +6325636098

Email: mdeguzman24@gmail.com

\section{Introduction}

Depression and anxiety are the most common mental disorders among medically ill patients admitted in the general hospital with a reported prevalence of $10 \%-50 \%{ }^{1}$ Being the final common pathway resulting from the interaction of biological, psychological and social factors, ways of improving the identification of psychiatric morbidity need to be found, because this can significantly impair the course of treatment and management of the medical illness in patients admitted to the general hospital. The under-recognition of psychiatric disorders is handicapped by the biomedical view of medical illness, which focuses more on physical signs and symptoms to the exclusion of psychological problems. This makes it difficult for the clinician to recognize promptly, to assess and to manage adequately any psychological distress among the medically-ill. This difficulty is reinforced by the patients' unwillingness to disclose any emotional problems and by the medical staff's reluctance to inquire about psychological problems because of the stigma of mental illness. ${ }^{2}$ Failure to recognize and treat medically-ill patients with psychiatric morbidity can significantly influence the course of medical illness, lengthen the duration of hospital stay, and lead to the patients' poor compliance to medication and treatment follow-ups. On the other hand, finding ways of improving the identification and treatment of psychological morbidity in the medically-ill have resulted in better patient adjustment, reduced symptoms, and influence the course of the disease towards a better quality of life, and eventually decrease the overall costs of medical services. ${ }^{3}$ For example, besides medications, psychosocial interventions (e.g. preoperative counseling, support groups, behavioral modifications) have shown to be cost-effective by decreasing the duration of hospital stay and the frequency of hospital admissions among medically-ill patients. ${ }^{4}$

One of the three potential methods to decrease the under-diagnosis of depression and anxiety, is the use of a self-report questionnaire to diagnose depression and anxiety. Efficient and economical methods of routinely screening for anxiety and depression in medically-ill patients would be advantageous. $^{5}$ A self-assessment approach warrants evaluation because it has the advantage of ease of administration and economy of clinician's time, as well as, 
provide satisfactory screening of depression and anxiety with the hope that this can lead to further psychiatric evaluation and treatment. ${ }^{6}$

Screening tests are not intended to be diagnostic, but the most important indication of the usefulness of the test is when the screening test separates the ill from well persons. To choose a good screening test, there are two important factors that need to be considered. First, is the feasibility of using a questionnaire in such a busy clinical setting as a tertiary hospital. The scale should be brief, cost-effective, and could easily be applied in all possible types of clinical setting (e.g. in-patient, out-patient, community screening). Secondly, for it to be an effective screening instrument, it has to reduce morbidity of the two most common clinical problems presenting in the medically-ill, depression and/or anxiety. And finally, its acceptability, that the instrument is easy to administer with a minimum discomfort on the part of the patient, as they are expected to complete the questionnaire in a short period of time.

Screening tests for depression and anxiety have never become widely used in the medically-ill in our set-up, despite the existence of a high prevalence of anxiety and depression. Performances of several questionnaires have been evaluated as to their acceptability, availability and practicality. There was the General Health Questionnaire
$(G H Q),{ }^{7}$ a 60 -item scale to measure general psychiatric distress which was too long for use with sick patients. There was also the Zung Depression Scale (SDS),, 8 a 20-item scale which was focused on the 'physiological' aspects of depression. And, there was the Beck Depression Inventory $(B D I),{ }^{9}$ a 21-item which was impractical for wide-scale screening because the items were intended to be read out by the interviewer. Finally, the Hospital Anxiety and Depression Scale (HADS), a self-report questionnaire for use with the medically-ill patients, developed by Zigmond and Snaith ${ }^{10}$ was chosen for validation, since it was specifically designed for use with the medically-ill, and being brief, was acceptable in any clinical setting. The Hospital Anxiety and Depression Scale (HADS) was designed to identify possible and probable cases of depression and anxiety disorders among the medically-ill patients. It only includes psychological symptoms, while the somatic items which could be attributed to the physical illness have been omitted. It is a 14-item, self-assessment questionnaire, composed of 7items for both the anxiety subscale and depression subscale.

More than 200 published studies worldwide have reported experiences with the HADS have been carried out in all types of medical settings and having been translated in more than 50 different languages. In an updated literature review by Hermann $\mathrm{C}$, he concluded that "the HADS is a

Table 1. Sensitivity, specificity and positive predictive value of the HADS / HADS-P optimal cut-off values from review of literature

\begin{tabular}{|c|c|c|c|c|c|c|c|c|c|c|c|c|c|c|}
\hline \multirow[t]{2}{*}{ Reference } & \multirow[t]{2}{*}{$\begin{array}{c}\text { Diagnostic } \\
\text { System }\end{array}$} & \multirow[t]{2}{*}{ Diagnosis } & \multirow[t]{2}{*}{$\begin{array}{c}\text { Patient } \\
\text { Population }\end{array}$} & \multirow[t]{2}{*}{$\mathbf{n}$} & \multicolumn{3}{|c|}{$\begin{array}{c}\text { Optimal cut-off } \\
\text { Values }\end{array}$} & \multicolumn{3}{|c|}{ Sensitivity } & \multicolumn{3}{|c|}{ Specificity } & \multirow[t]{2}{*}{$\begin{array}{c}\text { PPV } \\
\%\end{array}$} \\
\hline & & & & & A & D & $\mathrm{T}$ & A & D & $\mathrm{T}$ & A & D & $\mathrm{T}$ & \\
\hline $\begin{array}{l}\text { Wilkinson and } \\
\text { Barczak (1988) }\end{array}$ & DSM-III & $\begin{array}{l}\text { Anxiety, } \\
\text { depression }\end{array}$ & Primary Care & 100 & & & $8+$ & & & 0.90 & & & 0.86 & \\
\hline $\begin{array}{l}\text { Constantini et al } \\
\text { (1999) }\end{array}$ & DSM-III & $\begin{array}{l}\text { Anxiety, } \\
\text { depression }\end{array}$ & Breast Cancer & 197 & & & $10+$ & & & 0.84 & & & 0.74 & \\
\hline Hall et al (1999) & DSM-III & $\begin{array}{l}\text { Anxiety, } \\
\text { depression }\end{array}$ & Breast Cancer & 266 & $7+$ & $7+$ & $12+$ & 0.72 & 0.37 & 0.57 & 0.80 & 0.93 & 0.93 & \\
\hline $\begin{array}{l}\text { Hopwood et al } \\
\text { (1991) }\end{array}$ & DSM-III & $\begin{array}{l}\text { Anxiety, } \\
\text { depression }\end{array}$ & Breast Cancer & 81 & $11+$ & $11+$ & $18+$ & 0.75 & 0.75 & 0.81 & 0.90 & 0.75 & 0.89 & 49.6 \\
\hline $\begin{array}{l}\text { Clarke et al } \\
(1993)\end{array}$ & DSM-IIIR & MDD & $\begin{array}{l}\text { General } \\
\text { Hospital }\end{array}$ & 179 & & $10+$ & $21+$ & & 0.71 & 0.76 & & 0.92 & 0.93 & \\
\hline $\begin{array}{l}\text { Razavi et al } \\
\text { (1992) }\end{array}$ & DSM-IIIR & $\begin{array}{l}\text { Adjustment, } \\
\text { anxiety, } \\
\text { depression }\end{array}$ & Cancer & 117 & & & $10+$ & & & 0.84 & & & 0.66 & 50.0 \\
\hline \multirow[t]{4}{*}{ Abiodum (1994) } & ICD-9 & $\begin{array}{l}\text { Anxiety, } \\
\text { depression }\end{array}$ & $\begin{array}{l}\text { Medical and } \\
\text { Surgical }\end{array}$ & 275 & $8+$ & $8+$ & & 0.85 & 0.91 & & 0.87 & 0.87 & & \\
\hline & & & Gynecological & 233 & $8+$ & $8+$ & & 0.91 & 0.92 & & 0.87 & 0.89 & & \\
\hline & & & Antenatal & 240 & $8+$ & $8+$ & & 0.93 & 0.90 & & 0.90 & 0.91 & & \\
\hline & & & Community & 330 & $8+$ & $8+$ & & 0.88 & 0.90 & & 0.91 & 0.91 & & \\
\hline $\begin{array}{l}\text { Silverstone } \\
\text { (1996) }\end{array}$ & DSM-IV & $\begin{array}{l}\text { Modified } \\
\text { MDD }\end{array}$ & $\begin{array}{l}\text { General } \\
\text { medical }\end{array}$ & 153 & & $8+$ & $17+$ & & 1.00 & 1.00 & & 0.73 & 0.75 & \\
\hline $\begin{array}{l}\text { Ramirez et al } \\
(1995)\end{array}$ & $\begin{array}{l}\text { Bedford } \\
\text { criteria }\end{array}$ & $\begin{array}{l}\text { Anxiety, } \\
\text { depression }\end{array}$ & Breast cancer & 91 & & & $11+$ & & & 0.84 & & & 0.66 & \\
\hline
\end{tabular}

PPV: Positive predictive value; A: Anxiety subscale of the HADS / HADS-P ; D: Depression subscale of the HADS / HADS-P ; MDD: Major Depressive Disorder; PSE: Present State Examination; T: Total score of the HADS / HADS-P

* For example, $8+$ means equal to or above 8. 
reliable and valid instrument for assessing anxiety and depression in medically-ill patients." 11 The HADS gave clinically meaningful results as a psychological screening tool, in clinical group comparisons and in co-relational studies with several aspects of the medical illness and quality of life. It is sensitive to changes both during the course of the illness and in response to psychotherapeutic and psychopharmacological interventions. ${ }^{11}$

The findings of the 10 papers reporting sensitivity and specificity were summarized according to the population studied in Table 1. A review of validation data and clinical results based on international experience with the HADS revealed variation in both optimal cut-off values or threshold values as determined by a Receiver Operating Characteristics (ROC) curve by Hsiao JK et al. ${ }^{12}$ According to Hermann C., the reported variations in sensitivity and specificity were probably due to differences in diagnostic systems, in "gold standards", in the HADS translations utilized, as well as, differences in the methodologies and sample populations in the administration of the HADS. With a threshold of HADS score of $8+$, the sensitivity and specificity of the HADS were most often found to be in the range of $70 \%$ to $90 \% .^{13}$ The study concluded that the HADS performed well in assessing the severity of anxiety and depression in both psychiatric and primary care patients, in the medical clinics and hospitals, as well as, in the general population.

Considering its usefulness, the translation of the HADS to Pilipino was initiated by Pfizer pharmaceuticals to be used in a clinical trial. HADS was translated to Pilipino by 2 local translators, a lay person from the Filipino Institute of Translators and a clinician. Once a consensus was reached, it was back translated and evaluated by the designer of the clinical trial protocol to determine its faithfulness to the HADS. The HADS-Pilipino (HADS-P) was eventually created and approved to be tested on a selected sample and cognitive debriefing was carried out to determine if there was proper understanding of the content and form.

Given the availability and the acceptability of the questionnaire, the main objective of this study is primarily, to determine the prevalence of anxiety and/or depression in the medically-ill. Secondly, to determine the validity of the Hospital Anxiety and Depression Scale-Pilipino (HADS / HADS-P) and to determine the HADS / HADS-P optimal cut-off score for Filipinos given a maximal diagnostic contribution by using the Receiver Operating Characteristic (ROC) curve.

\section{Methods}

The study utilized a cross-sectional design. Primary data was obtained from the in-patient ward of the hospital. The presence of anxiety and depression were considered as the dependent variables. The independent variables were the demographic factors: age, gender, civil status and educational attainment; history of mental illness, medical diagnosis, duration of stay and the medical settings or wards. The subjects were all patients admitted to the medical and surgical wards of the Philippine General Hospital, except those admitted to the Psychiatry ward (due to severity of mental illness) and the Ophthalmology ward (due to poor visual acuity). Subjects were chosen from the list of patients using simple random sampling considering the high turnover of in-patients from the wards. Inclusion criteria: patients who are admitted to the medical and surgical charity wards; who are at least $\geq 18$ years old; able to read and write; able to understand either Filipino/English; and must give their informed consent. Exclusion criteria: patients unable to understand either Filipino and/or English; suffering from any severe physical discomfort; necessitating an informant; and, unwilling to participate in the study.

The HADS / HADS-P questionnaire was administered to the patients, followed by a psychiatric interview, which served as the gold standard. The diagnostic evaluation was done by a clinical psychiatrist, who was blinded to the questionnaire responses and HADS / HADS-P scores. The psychiatric interview used the Clinical Interview Schedule by Goldberg DP, et al, ${ }^{13}$ with additional questions in order to apply the standardized psychiatric diagnostic criteria.

The purpose of the study, with its risks and benefits, were explained to the subjects. Informed consent was obtained and those who refused to answer the HADS / HADS-P questionnaire and/or who refused to be interviewed were identified and considered as "dropouts". Patients who requested to withdraw their participation were allowed to do so without any sanctions. All the data collected were kept confidential. The primary physicians of patients who were diagnosed to have clinical depression and/or anxiety were informed through written progress notes in the medical charts. Recommendations were given for referral to the Consultation Liaison Section of the Department of Psychiatry and Behavioral Medicine for treatment and management.

The proportion used for the computations were based on the observed prevalence of depression and anxiety in local studies. The sample size estimation was done using the formula for a cross-sectional study, estimation of the population proportion $\mathrm{P}$, for stratified random sampling. A total adjusted sample size of 710 patients was needed in order to be $95 \%$ confident that the proportion by sensitivity and specificity is estimated. This takes into account the attrition rate in the form of non-responses such as withdrawal of subject from the study and invalid questionnaires due to incorrect or incomplete responses.

The principal investigator reviewed the work accomplished after having completed the HADS / HADS-P questionnaire and the results of the interview within 24 
hours. Particular attention was given to information legibility, missing answers, inconsistencies, and lack of uniformity. All the forms were re-checked for accuracy and completeness. All the data collected were encoded into the computer using Microsoft EXCEL (Microsoft Corporation Windows XP Version 2007). It was processed and analyzed using the Intercooled STATA 9.1 software program.

\section{Results}

A total of 710 in-patients were interviewed from the different medical and surgical charity wards of the Philippine General Hospital. Of the total number of 710 , $7.3 \%$ (52/710) were excluded due to non-participation, of which 47 patients refused to answer the HADS / HADS-P questionnaires and 5 patients had inconsistent responses. A total number of 658 patients were included in the analysis, with a $94 \%$ response rate. Table 2 shows the distribution of the patients according to demographic profile: age, gender, civil-status and the highest educational attainment. As to age, majority of the subjects were from the young adult age group of $18-35$ years (43.3\%), followed by the late adult age group of $\geq 45$ years $(38.1 \%)$, and then the middle adult age group of 36-44 years (18.1\%). The mean age of the subjects were 41.84 years (S.D. \pm 26.1 ). The median age was 38 years with an age range of $18-82$ years. As to gender, the female patients $(54.1 \%)$ were more than the males $(45.9 \%)$ in the subject population. As to civil status, majority of the patients were married $(60.4 \%)$, followed by those who were single (26.1\%); and those who were widowed/separated (13.2\%). In terms of the highest level of educational attainment, majority of the subjects had reached high school levels (53.2\%), followed by the elementary levels $(26.9 \%)$, and the college levels (19.9\%).

Four major categories were used to classify the subjects according to their medical and surgical diagnosis based on the review of medical records. Most of the patients were diagnosed to have a surgical illness (39.1\%), followed by trauma $(29.5 \%)$, medical diagnosis $(19.3 \%)$, and cancer $(17.2 \%)$. The distribution of the patients according to the duration of hospital stay (in days) was defined as from the time of admission until the time when the diagnostic psychiatric evaluation was accomplished. Majority of the patients stayed for less than 1 week duration, 0 - 7 days $(47.0 \%)$, while the rest stayed for 8 - 14 days $(25.5 \%)$ and $>14$ days $(27.5 \%)$. The mean duration of hospital stay was 18.40 days (S.D. \pm 30.5 days) with a median of 8 days and a range of $1-195$ days. The distribution as to the presence or absence of a history of mental illness revealed that majority of the patients admitted never having had a history of mental illness $(91.3 \%)$, while $<10 \%$ admitted a history of mental illness (8.7\%). Regarding the distribution of inpatient admissions as to the medical settings, the results revealed that majority of the patients came from three major
Table 2. Distribution of Patients according to Demographic profile, Medical diagnosis, Duration of Hospital stay, History of Mental Illness, and Medical Settings, Diagnosis of Clinical Depression and/or Anxiety based on Psychiatric evaluation, CGI, PGH.

\begin{tabular}{|c|c|c|}
\hline $\begin{array}{c}\text { Demographic profile } \\
\text { Age (years) }\end{array}$ & No. $/ \mathrm{n}=658$ & Percent \\
\hline $18-35$ & 285 & 43.3 \\
\hline $36-44$ & 119 & 18.1 \\
\hline$\geq 45$ & 254 & 38.1 \\
\hline Mean: & \multicolumn{2}{|c|}{41.84 years $($ S.D. \pm 26.1$)$} \\
\hline Median: & \multicolumn{2}{|c|}{38 years } \\
\hline Range (min, max): & \multicolumn{2}{|l|}{18,82 years } \\
\hline \multicolumn{3}{|l|}{ Gender } \\
\hline Male & 302 & 45.9 \\
\hline Female & 356 & 54.1 \\
\hline \multicolumn{3}{|l|}{ Civil status } \\
\hline Single & 173 & 26.1 \\
\hline Married/live-in & 398 & 60.5 \\
\hline Separated/ Widow & 87 & 13.2 \\
\hline \multicolumn{3}{|l|}{ Educational attainment } \\
\hline Elementary & 177 & 26.2 \\
\hline High School & 350 & 53.9 \\
\hline College & 131 & 19.9 \\
\hline \multicolumn{3}{|l|}{ Medical Diagnosis } \\
\hline Medical & 127 & 19.3 \\
\hline Surgical & 224 & 39.1 \\
\hline Cancer & 113 & 17.1 \\
\hline Trauma & 194 & 29.5 \\
\hline \multicolumn{3}{|l|}{ Duration of Hospital stay } \\
\hline $0-7$ days & 309 & 47.0 \\
\hline $8-14$ days & 168 & 25.5 \\
\hline$>14$ days & 181 & 27.5 \\
\hline Mean: & \multicolumn{2}{|c|}{18.40 days $($ S.D. \pm 30.5) } \\
\hline Median: & \multicolumn{2}{|c|}{8 days } \\
\hline Range (min, max): & \multicolumn{2}{|l|}{1,195 days } \\
\hline \multicolumn{3}{|l|}{ History of mental illness } \\
\hline No history of mental illness & 601 & 91.3 \\
\hline$(+)$ history of mental illness & 57 & 8.7 \\
\hline \multicolumn{3}{|l|}{ Medical settings } \\
\hline Medicine & 47 & 7.1 \\
\hline Cancer & 42 & 6.4 \\
\hline Obstetrics and Gynecology & 120 & 18.2 \\
\hline Surgery & 119 & 18.1 \\
\hline Orthopedics & 148 & 22.5 \\
\hline Neurology/ Neurosurgery & 9 & 1.2 \\
\hline Otorhinolaryngology & 57 & 8.7 \\
\hline Rehabilitation Medicine & 47 & 7.1 \\
\hline Trauma Unit & 57 & 8.7 \\
\hline Burn Unit & 12 & 1.8 \\
\hline \multicolumn{3}{|c|}{ Diagnosis of Depression and Anxiety } \\
\hline Normal & 297 & 45.1 \\
\hline Anxiety & 94 & 14.3 \\
\hline Depression & 177 & 26.9 \\
\hline Depression and anxiety & 90 & 13.7 \\
\hline \multicolumn{3}{|l|}{ Clinical Global Impression } \\
\hline Normal & 297 & 45.1 \\
\hline Mild & 79 & 12.1 \\
\hline Moderate & 112 & 17.0 \\
\hline Severe & 170 & 25.8 \\
\hline
\end{tabular}

departments: Orthopedics (22.5\%), followed by Obstetrics and Gynecology (18.2\%) together with Surgery (18.1\%). Less than $10 \%$ for each of the patient population came from the 
following respective departments: Otorhinolaryngology and Trauma (8.7\%); Rehabilitation Medicine (7.1\%) and Medicine (7.1\%), respectively; followed by the Cancer Institute $(6.4 \%)$; then the Burn Unit (1.8\%) and Neurology/ Neurosurgery $(1.4 \%)$. Finally, the distribution as to the severity of depression and/or anxiety based on the Clinical Global Depression (CGI) on psychiatric evaluation, showed $12.1 \%$ had a mild degree of depression and/or anxiety. Those with a moderate degree of clinical depression and/or anxiety comprised $17.0 \%$, while $25.8 \%$ had a severe form of clinical depression. These had strong implications for the need for psychiatric referral for treatment and management.

\section{Prevalence of Depression and Anxiety}

In the study population, the prevalence of clinical depression is $26.9 \%$; followed by anxiety disorder with a prevalence of $14.3 \%$, and prevalence of a 'mixed diagnosis' of depression and anxiety was $13.7 \%$ based on psychiatric evaluation. These estimates represent the proportion of medically-ill patients having depression and anxiety. The conditions that featured prominent depression, anxiety, or both as a cardinal characteristic were pooled into one category of depression and anxiety, which showed an overall prevalence rate of $54.9 \%$.

Table 3 shows the prevalence of depression and anxiety according to demographic factors, duration of hospital stay, medical settings, and the presence/ absence of a history of mental illness.

As to age group, the proportion of patients with depression and anxiety were significantly higher in the younger adult age group of 18-35 years (60.7\%), followed by the middle adult age group 36-44 years (52.9\%), and the older adult age group $>45$ years $(49.2 \%)$. It can be observed that as the age increases, the prevalence for depression and anxiety decreases. The difference by age group was significant ( $\mathrm{X}^{2}$ with $2 \mathrm{df}=7.376 ; \mathrm{p}$-value $\left.=0.025\right)$. As to gender, the prevalence of depression and anxiety was higher among males $(57.9 \%)$ than females $(52.2 \%)$. However, the difference between males and females was not significant and can be attributed to chance $\left(\mathrm{X}^{2}\right.$ with $2 \mathrm{df}=2.144$; $\mathrm{p}$ value $=0.143$ ). As to civil status, the prevalence of depression and anxiety was higher among those who were married/livein $(59.3 \%)$, followed by single (55.5\%) and widow/separated $(33.3 \%)$. The difference is significant $\left(X^{2}\right.$ with $2 \mathrm{df}=19.471 ; \mathrm{p}-$ value $<0.001)$. There exist an inversely proportional relationship between educational attainment and the prevalence of depression and anxiety. As educational attainment increases, from elementary to college, the prevalence of depression and anxiety decreases. Those in the lowest educational levels had the highest prevalence for depression and anxiety, both in the elementary level (56.9\%) and in the high school level (57.1\%), followed by those in the college level $(37.4 \%)$. This difference was found to be highly
Table 3. Prevalence of Depression and Anxiety according to Selected Demographic Factors, PGH

\begin{tabular}{|c|c|c|c|c|c|c|}
\hline \multirow{3}{*}{$\begin{array}{c}\text { Demographic } \\
\text { Profile }\end{array}$} & \multicolumn{2}{|c|}{ Normal } & \multicolumn{3}{|c|}{ (+) Depression and Anxiety } & \multirow[b]{3}{*}{ Total } \\
\hline & \multirow[b]{2}{*}{ No. } & \multirow[b]{2}{*}{$\%$} & \multirow[b]{2}{*}{ No. } & \multirow[b]{2}{*}{$\%$} & \multirow{2}{*}{$\begin{array}{c}95 \% \\
\text { Confidence } \\
\text { Interval } \\
\end{array}$} & \\
\hline & & & & & & \\
\hline \multicolumn{7}{|l|}{ Age (years) } \\
\hline $18-35$ & 112 & 39.3 & 173 & 60.7 & $54.8-66.4$ & 285 \\
\hline $36-44$ & 56 & 47.1 & 63 & 52.9 & $43.6-62.1$ & 119 \\
\hline$\geq 45$ & 129 & 50.8 & 125 & 49.2 & $49.9-55.5$ & 254 \\
\hline & & & \multicolumn{4}{|c|}{ Chi-square $=7.376 ; \mathrm{p}-$ value $=0.025$} \\
\hline \multicolumn{7}{|l|}{ Gender } \\
\hline Male & 127 & 42.1 & 175 & 57.9 & $52.1-63.5$ & 302 \\
\hline Female & 170 & 47.8 & 186 & 52.2 & $46.9-57.5$ & 356 \\
\hline & & & \multicolumn{4}{|c|}{ Chi-square $=2.144 ; \mathrm{p}-$ value $=0.143$} \\
\hline \multicolumn{7}{|l|}{ Civil status } \\
\hline Single & 77 & 44.5 & 96 & 55.5 & $47.8-63.0$ & 173 \\
\hline Married/live-in & 162 & 40.7 & 236 & 59.3 & $54.3-64.1$ & 398 \\
\hline Separated/ & 58 & 66.7 & 29 & 33.3 & $23.8-44.3$ & 87 \\
\hline \multicolumn{7}{|l|}{ Widow } \\
\hline & & & \multicolumn{4}{|c|}{ Chi-square $=19.471 ; p-$ value $<0.001$} \\
\hline \multicolumn{7}{|l|}{$\begin{array}{c}\text { Educational } \\
\text { attainment }\end{array}$} \\
\hline Elementary & 65 & 36.7 & 112 & 56.9 & $49.6-63.8$ & 197 \\
\hline High School & 150 & 42.7 & 200 & 57.1 & $51.8-62.4$ & 350 \\
\hline College & 82 & 62.6 & 49 & 37.4 & $29.2-46.3$ & 131 \\
\hline & & & \multicolumn{4}{|c|}{ Chi-square $=23.410 ; p-$ value $<0.001$} \\
\hline \multicolumn{7}{|l|}{$\begin{array}{l}\text { Medical } \\
\text { diagnosis }\end{array}$} \\
\hline $\begin{array}{l}\text { Medical } \\
\text { diagnosis }\end{array}$ & 94 & 39.2 & 146 & 60.8 & $54.3-67.0$ & 240 \\
\hline Surgical & 203 & 48.6 & 215 & 51.4 & $46.5-56.3$ & 418 \\
\hline & & & \multicolumn{4}{|c|}{ Chi-square $=5.438 ; \mathrm{p}-$ value $=0.020$} \\
\hline \multicolumn{7}{|l|}{$\begin{array}{l}\text { Duration of } \\
\text { Hospital Stay }\end{array}$} \\
\hline $0-7$ days & 140 & 45.3 & 169 & 54.7 & $49.0-60.3$ & 309 \\
\hline 8 - 14 days & 101 & 60.1 & 67 & 39.9 & $32.5-47.7$ & 168 \\
\hline$>14$ days & 56 & 30.9 & 125 & 69.1 & $61.7-75.6$ & 181 \\
\hline & & & Chi- & uare $=$ & $965 ; p-$ valu & $=0.000$ \\
\hline $\begin{array}{c}\text { History of } \\
\text { mental illness }\end{array}$ & & & & & & \\
\hline $\begin{array}{l}\text { No History of } \\
\text { mental illness }\end{array}$ & 275 & 45.8 & 326 & 54.2 & $50.2-58.3$ & 601 \\
\hline $\begin{array}{l}(+) \text { History of } \\
\text { mental illness }\end{array}$ & 22 & 38.6 & 35 & 61.4 & $47.6-73.8$ & 57 \\
\hline & & & Chi & uare $=$ & .078; $\mathrm{p}$ - value & $=0.299$ \\
\hline $\begin{array}{l}\text { Medical } \\
\text { Settings }\end{array}$ & & & & & & \\
\hline Medicine & 15 & 31.9 & 32 & 68.1 & $52.7-80.5$ & 47 \\
\hline Cancer & 20 & 47.6 & 22 & 52.4 & $36.6-67.7$ & 42 \\
\hline $\begin{array}{l}\text { Obstetrics and } \\
\text { Gynecology }\end{array}$ & 49 & 40.8 & 71 & 59.2 & $49.8-67.9$ & 120 \\
\hline Surgery & 53 & 44.5 & 66 & 55.5 & $46.1-64.5$ & 119 \\
\hline Orthopedics & 83 & 56.1 & 65 & 43.9 & $35.9-52.3$ & 148 \\
\hline Neurology/ & 6 & 66.7 & 3 & 33.3 & $9.0-69.1$ & 9 \\
\hline Neurosurgery & & & & & & \\
\hline $\begin{array}{l}\text { Otorhinolaryng } \\
\text { ology }\end{array}$ & 35 & 61.4 & 22 & 38.6 & $26.3-52.4$ & 57 \\
\hline Rehabilitation & 14 & 29.8 & 33 & 70.2 & $54.9-82.2$ & 47 \\
\hline Medicine & & & & & & \\
\hline Trauma Unit & 18 & 31 & 39 & 68.4 & $54.6-79.7$ & 57 \\
\hline Burn Unit & 4 & 6 & 8 & 66.7 & $35.4-88.7$ & 12 \\
\hline & & & Chi- & uare $=$ & $649 ; \mathrm{p}-\mathrm{valu}$ & $=0.001$ \\
\hline
\end{tabular}


significant $\left(\mathrm{X}^{2}\right.$ with $2 \mathrm{df}=23.410 ; \mathrm{p}$-value $\left.<0.001\right)$. The economic and social burden of care in the medically-ill is highly considered a contributing factor of depression and anxiety, given the marginalized population in the charity wards.

According to medical diagnosis, the prevalence of depression and anxiety was higher among those with a medical diagnosis $(60.8 \%)$ compared to those with a surgical diagnosis $(51.4 \%)$, which was significant $\left(\mathrm{X}^{2}\right.$ with $2 \mathrm{df}=$ 5.438; $\mathrm{p}$-value $<0.020$ ). Duration of hospital stay is defined as the number of days of hospitalization from the time of admission up to the time of psychiatric evaluation. As to duration of hospital stay, the prevalence was highest among those who stayed longest $>14$ days $(69.1 \%)$ than those who stayed for 7 days or less $(54.7 \%)$. On the other hand, those who stayed between 8-14 days (39.9\%) had the lowest figure. The variation in prevalence was significant $\left(X^{2}\right.$ with 2 $\mathrm{df}=29.965$; $\mathrm{p}$-value $=0.000)$. As to history of mental illness, the prevalence of depression and anxiety was higher among those with a (+) history of mental illness $(61.4 \%)$ than those with negative history of mental illness (54.2\%). However, the difference was not statistically significant $\left(X^{2}\right.$ with $2 \mathrm{df}=$ 1.078; $\mathrm{p}$-value $=0.299$ ).

The prevalence of depression and anxiety, according to medical settings, was found to be highest in the departments of Rehabilitation Medicine (70.2\%), Trauma Unit $(68.4 \%)$, Medicine $(68.1 \%)$ and the Burn Unit $(66.7 \%)$. This was followed by Obstetrics and Gynecology (59.5\%), Surgery $(55.5 \%)$, Cancer Institute (52.4\%), Orthopedics $(43.9 \%)$, Otorhinolaryngology (38.6\%), Neurology and Neurosurgery $(33.3 \%)$. The differences in prevalence were highly significant $\left(\mathrm{X}^{2}\right.$ with $2 \mathrm{df}=28.649$; $\mathrm{p}$-value $\left.=0.001\right)$.

\section{Validation of the HADS / HADS-P}

The validity of the HADS / HADS-P screening test was assessed by determining its sensitivity and specificity. According to Baldessarini RJ, et al, the proportion of true positives identified by the test defines its sensitivity, while the proportion of true negatives defines its specificity. ${ }^{14}$ Given that that sensitivity and specificity are dependent on the ratio of high and low scores in the sample, there is no definite index of the HADS / HADS-P screening test's performance, but instead pairs of sensitivities and specificities for each possible cut-off and for each possible pairs of group were compared. The positive predictive value (PPV) was also calculated for each cut-off score. This value gives the probability of being a case, $(+)$ depression and/or anxiety at a precise cut-off point. The PPV was also used as an estimate of the screening potential of the HADS / HADS-P.

Case identification will involve score summation and classification will depend on whether a person scores below or above a cut-off score. Table 4 is the summary table of the sensitivity, specificity and PPV of each score. There is a trade-off between sensitivity and specificity, where increased specificity is obtained at the expense of decreased sensitivity for all screening tests. The choice of the HADS / HADS-P cut-off will depend on the aspect which is considered most important. According to Baldessarini, ${ }^{14}$ when choosing a cut-off, many clinical and non-clinical factors are often relevant. Since the prevalence of depression and anxiety among all persons varies widely, it also varies among different clinical settings: in-patient, out-patient, community-based samples and research units. According to Baldessarini RJ, et al, the ideal cut-off score can be influenced by the prevalence of the disorders, and the cut-off score must be adapted accordingly.

Table 4. Summary Table. Sensitivity, specificity and positive predictive value of the HADS / HADS-P scale at a selection of cut-off scores when discriminating between medical and surgical patients admitted to PGH with and without depression and anxiety

\begin{tabular}{cccc}
\hline & \multicolumn{3}{c}{ Validity of the HADS / HADS-P } \\
\cline { 2 - 4 } HADS / HADS-P & & & \\
Cut-off scores & Sensitivity & Specificity & PPV \\
\hline 6 & & & \\
\hline 7 & 0.95 & 0.44 & 0.67 \\
8 & 0.95 & 0.44 & 0.67 \\
9 & 0.91 & 0.51 & 0.69 \\
10 & 0.84 & 0.56 & 0.70 \\
11 & 0.81 & 0.64 & 0.73 \\
12 & 0.75 & 0.70 & 0.75 \\
13 & 0.69 & 0.75 & 0.76 \\
14 & 0.61 & 0.82 & 0.80 \\
15 & 0.51 & 0.84 & 0.81 \\
16 & 0.41 & 0.90 & 0.83 \\
17 & 0.34 & 0.91 & 0.84 \\
18 & 0.33 & 0.94 & 0.89 \\
& 0.26 & 0.96 & 0.87 \\
\hline
\end{tabular}

In this study, the HADS / HADS-P cut-off score associated with a high sensitivity is recommended to be used in the in-patient wards where the prevalence of depression and anxiety is high, because it was desirable to receive a $100 \%$ detection rate. Therefore, the cut-off recommended for screening is a HADS / HADS-P score of $7 \pm$ with a sensitivity of $95 \%$ and a specificity of $45 \%$ and a PPV of $67 \%$. While this was achieved with a cut-off score of 7 , it was only at the expense of including a high proportion of false positives, which is expected to increase the interview load of the clinician. A high false positive rate may be related to acute distress reaction (e.g. due to hospitalization) which may give rise to a high level of psychological distress and therefore, high scores on the HADS / HADS-P. One must always consider that self-reported distress is not always correlated with the presence of a given disorder. In clinical practice, patients with high scores warrant further 
assessment with a brief clinical interview, as it is possible to discriminate between true cases of depression and anxiety from false positives on this basis. A high false negative rate could be related to social desirability which leads patients to under-report on self-reported measures their psychological distress, thus revealing low scores on the HADS / HADS-P.

The Receiver Operating Characteristics (ROC) analysis, according to Murphy JM, et al, is a technique particularly useful in making clinical decision analysis as it extends to assessment of tests. ${ }^{15}$ The sensitivity and specificity of the HADS / HADS-P were computed at different cut-off points. There is the usual trade-off given a high sensitivity and a corresponding sensitivity which is presented in the Receiver Operating Characteristics (ROC) curve. Hsiao JK, et al defined the ROC curve as a plot of the balance between sensitivity and specificity for a diagnostic test. The perfect test is when there is no overlap in the values of the sensitivity and specificity between the diseased (with depression and anxiety) and non-diseased groups (normal). On the contrary, if the two categories overlap completely, as the cut-off point varies, the true positives and the false positives will increase uniformly, and the ROC curve will be a diagonal connecting the lower left and upper right corners of the bottom, called the line of no information (random ROC). The less overlap between sensitivity and specificity, the better the HADS / HADS-P test performs, the further the ROC curve will be from the line of no information. The greater the distance between the HADS / HADS-P test's ROC curve and random ROC, the better the performance of the HADS / HADS-P.

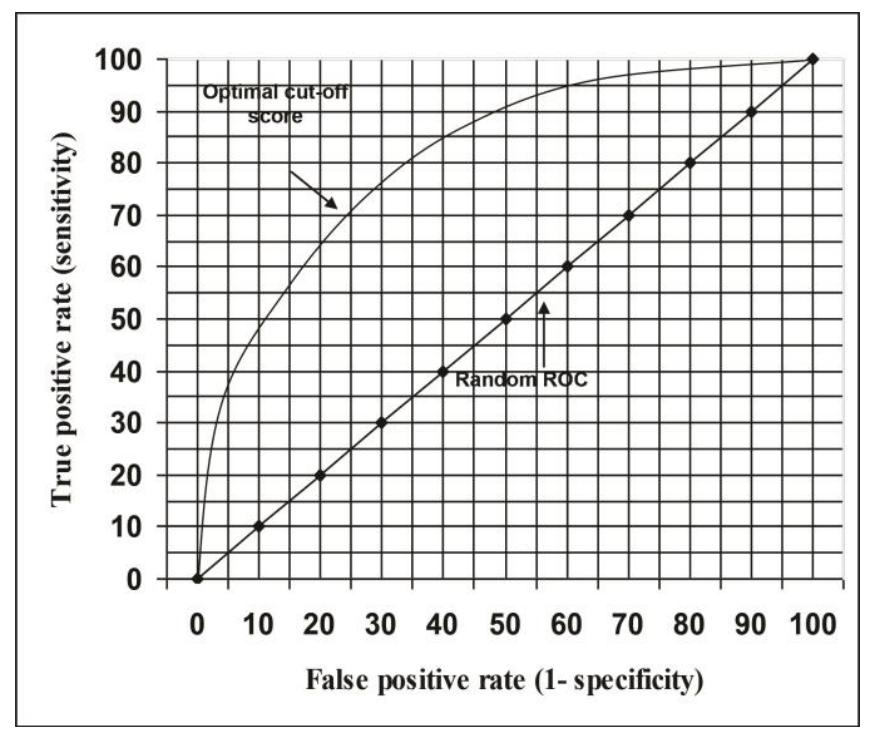

Figure 1. Receiver Operating Characteristics (ROC)

The area under the curve (AUC) is a useful index for the performance of the HADS / HADS-P, and is the way of measuring the distance of the ROC curve from the random ROC. The area under the curve under the ROC curve for the discrimination of depression and/or anxiety using the HADS / HADS-P cut-off was determined at 0.75. The AUC is depicted by the diagonal line from the lower left to the upper right of the ROC graph. The further the curve is from the diagonal line, a higher AUC (near 1.0), the better the performance of the HADS / HADS-P .

The ROC curve in Figure $\mathbf{1}$ presents all the possible pairs of sensitivity and specificity, using the true positive rate on the $y$-axis and the false positive rate( 1 - specificity) on the x-axis. The recommended optimal cut-off score is a HADS / HADS-P score of 11 , with a sensitivity of $75 \%$ and a specificity of $70 \%$, and a PPV of $75 \%$, which was found to be consistent with those found in literature.

\section{Discussion}

The prevalence of depression and anxiety in this study is consistent with what has been found in literature, internationally and locally. International studies by Mayou and Hawton ${ }^{16}$ reported the prevalence of depression and anxiety in the medically ill from $15 \%$ to $59 \%$. The local study by Perlas and Querijero determined the prevalence of psychiatric disorders among the chronic medically-ill patients in selected tertiary hospitals with depression having the highest prevalence at $32.1 \%$ and anxiety at $16.3 \%{ }^{17}$

In this study, among the medically-ill in-patients, the prevalence of depression is $26.9 \%$ and anxiety is $14.3 \%$. The prevalence of depression and anxiety was highest among those with a medical diagnosis compared to those with a surgical diagnosis and among those with a longer duration of hospital stay $>14$ days (number of days from the time of admission up to the time of psychiatric evaluation). As to demographic factors, the prevalence of depression and anxiety was highest among the younger adult age group of 18 - 35 years; among males; among those who are married/live-in; and, among those with a lower educational attainment.

Biases and limitations in this study cannot be discounted. First of all, there was selection bias in the selection of study participants for this study, as the investigator encountered some difficulty in implementing the simple random sampling having to consider the dynamic factors involved with patients' admissions. In simple random sampling, it is ideal that each patient admitted in the general hospital have an equal chance to be included in the study sample. Primary consideration had to be given to the accessibility of the patients; the severity of their medical illness (e.g. timing; the patient's comfortableness in answering the self-report questionnaire and subjecting themselves to a diagnostic psychiatric evaluation); and, other patient-factors, e.g. poor cognitive functions, pain and discomfort. There was also a high turnover of patients given 
an acute-treatment set-up of the hospital, making it difficult to follow-up patients for incomplete responses, for which reason they were considered as dropouts. As a result, there was selective participation, because only those who were identifiable were included and those who were not easily identifiable were excluded from the study. For example, if the eligible patients were not available or were not around at the time of the HADS / HADS-P administration for whatever reasons, then the patient in the next bed was selected. To complete the sample size, the investigator kept on substituting patients who were more accessible and were willing to participate. There was also accessibility bias, when the co-investigator admitted to choosing patients who are easily amenable and to whom she was easily drawn to. Despite attempts to control the sample bias, the investigators at least tried to minimize it. The manner of selection of actual study participants may definitely have some effect in the validity of the overall prevalence estimates of depression and anxiety. Most likely, the observed prevalence of this study may have overestimated the prevalence of depression and anxiety among those who stayed longer in the hospital and those with a medical diagnosis compared to those with a shorter duration of hospital stay and those with a surgical diagnosis.

The limitation in this study, primarily, is the diagnostic validity of the psychiatric diagnosis because of the marked overlap among clinical features of depression and anxiety and with various mental disorders. Depression and anxiety share a substantial component of general affective distress or "negative affectivity" according to Flint. ${ }^{18}$ This is the reason why, most patients with a principal diagnosis of depressive disorders have an additional diagnosis present, e.g. anxiety disorders and substance abuse disorders. At the basic level remains the issue of whether classification should be categorical or dimensional. With the considerable overlap in symptomatology, it is ideal to use the dimensional category, given a wide spectrum of depressive illnesses and anxiety disorders. The prevalence of depression and anxiety could have been lower if the dimensional categories of depressive disorders and anxiety disorders were utilized limiting the analysis to the major mental disorders. In so doing, major depressive disorder will be distinguished from adjustment disorder with depressed mood and dysthymia. Even categorizing them as mild, moderate and severe depression will be helpful since they require interventions designed to help the patients cope with their illness and control their psychological distress which arises during all the phases of diagnosis and treatment of their medical illness. The same is true for anxiety disorders as distinguished from adjustment disorders with anxious moods and generalized anxiety disorders as distinct categories. The prevalence of depression and anxiety in this study is consistent with the other studies provided that strict diagnostic criteria are used with a complete assessment of the target population. This was not a problem in this study though because of having one rater to do the diagnostic evaluation, thus minimizing variability in the diagnosis. It is only when we pooled the diagnostic categories into one case definition, was the prevalence of depression and anxiety found to be considerably higher at $54.86 \%$, which skewed the prevalence of depression and anxiety. And secondly, another limitation of the study was it being conducted among the medically-ill in-patients of one government tertiary hospital, so that the results may not be reflective and applicable in other clinical settings, unless a database is established documenting its psychometric properties.

According to Goldberg, in the absence of objective criteria, a diagnostic examination by a psychiatrist is assumed to be the most valid method of psychiatric case identification. The use of a screening test as a structured examination is considered an efficient and economical method for psychiatric illness in different patient populations. However, despite the reliability of the screening test, its validity still needs to be assessed. The HADS / HADS-P was developed to provide clinicians and researchers with a reliable, valid and practical tool for identifying the two most common forms of psychiatric illness in patients with medical illness. In this study, the HADS / HADS-P was validated as a screening instrument given the different cut-off scores. The optimal cut-off score recommended for Filipinos is a HADS / HADS-P score of 11 with a sensitivity of $75 \%$ and a specificity of $70 \%$, and a PPV of $75 \%$ based on ROC. The increased risk, the clinical benefits of early recognition and the large number of missed diagnoses suggest the potential usefulness of a depression and anxiety screening instrument.

The results with the use of the HADS / HADS-P as a screening test for depression and anxiety were consistent enough, making us confident that patients reporting certain symptoms would be diagnosed as a case. However, this confidence is tempered by the knowledge that most of the diagnosed patients do not report those symptoms. There are possible explanations why the HADS / HADS-P did not produce good separation between the true cases of having depression and/or anxiety from those who are normal or with no depression and anxiety, which would most likely affect the validity of the HADS / HADS-P. First, there could be information bias of the non-differential misclassification type because patients were noted to underreport their emotional symptoms on the HADS / HADS-P, resulting in lower scores on the HADS / HADS-P. This will tend to underestimate the results of the HADS / HADS-P.

Another possible bias to be considered is the lag time for the psychiatric interview. The lag time is defined as the time duration or time period, from the time the patient started answering the HADS / HADS-P up to the time the 
psychiatric evaluation was done on the same patient. The time period over which the severity of a disorder is to be assessed is a most important consideration. The presence of a clinical depressive or an anxiety disorder should be distinguished from depressive and anxiety symptoms which can change over a matter of time, according to Roberstone and Katona. ${ }^{19}$ Ideally there should be no lag time between the answering of the HADS/ HADS-P by the patient followed by the psychiatric interview conducted on the same patient, which should be done simultaneously. The aim of the HADS / HADS-P score should reflect the present state mood and not much difference was to be expected as to the respondent's current state during the psychiatric interview, if it was done on the day on which the respondent had completed the HADS / HADS-P interview schedule, as compared with having done the psychiatric interview one or two days after having completed the HADS / HADS-P interview schedule. Only in a minority of cases was the interviewed delayed. This time lag difference may have affected the validity of the HADS / HADS-P.

One disadvantage of the HADS / HADS-P is the low specificity with relatively high false positive rates. Thus, ideally, patients with high scores should be subjected to further evaluation by a brief semi-structured diagnostic interview by the clinician, as it is possible to discriminate those who are truly depressed and or anxious from those who are not on this basis. It is also suggested that the results be merely recorded with a view for re-assessment and follow-up at a later date if treatment were inappropriate at this time. It is also recommended on the part of the clinician that there be an awareness of the risk factors highly associated with depression and anxiety, before referring to a psychiatrist.

In using HADS / HADS-P as a screening instrument for depression and anxiety in the medically ill patients, the recommended optimal cut-off score for Filipino is a HADS / HADS-P score of 11 , with a sensitivity of $75 \%$ and a specificity of $70 \%$, and a PPV of $75 \%$.

\section{Recommendations}

There is a growing interface between hospital-based psychiatry and medical practice in the general hospital setting, in relation to depression and anxiety. The rationale for this is as follows: First, there is abundant evidence suggesting that prevalence of depression and/or anxiety in the medically-ill patients is high. Second, depression and anxiety is one of the main reasons for referral to the hospitalbased consultation liaison psychiatry service. Third, of the $30-60 \%$ of medically-ill hospitalized patients estimate to have psychiatric morbidities, only $1-3 \%$ received psychiatric consultations, which will lead to higher medical morbidity and mortality, increased health care costs and utilization; longer duration of hospital stay and recovery; and increased functional disability.

The HADS / HADS-P interview schedule has been validated as a reliable and effective screening instrument. The optimal cut-off score identified in this study was aimed at arriving at an acceptable balance in terms of accuracy and clinical feasibility, also considering the high prevalence of anxiety and /or depression. Thus, the HADS / HADS-P can be used not only as a screening tool but it can also be used as an ongoing method of assessing response to specific and effective treatment since they are brief and easily completed and have a high sensitivity. It has the advantage of being quick and easy to administer, with a high patient acceptability, and is capable of discriminating to a certain extent between cases of depression and anxiety. It is recommended, as the next step, that further researches be carried out utilizing the HADS / HADS-P as a screening instrument in different clinical settings (e.g. out-patients clinics, in medical specialty clinics, general hospital and community samples clinical practice). A database of the respondents from the different clinical settings can eventually be set-up to establish a comprehensive documentation of the HADS-P and its psychometric properties. This would establish the feasibility and usefulness of the HADS / HADS-P in any clinical setting to determine those who are at risk for depression and anxiety, but not as a sole basis for diagnosis and treatment. Even better, it should lead to a thorough psychiatric interview in which a definitive diagnosis can be made with prompt and adequate treatment initiated.

Finally, on interviewing a patient with depression and anxiety, apart from utilizing a standard assessment, it is important that the clinician be able to explore the patient's understanding of his/her disease and its implications, and the impact of hospitalization. It is also substantial to know the support systems available to the patients and their current psychosocial stressors, which may not be specifically related to the illness, but needs to be taken into account. Past crisis situations and how the patients' have coped with them, and their past psychosocial functioning will help complete the picture. All these considerations will serve not only as protective factors from developing depression and anxiety, but can also enhance and strengthen the patients' ability to cope with the illness and hospitalization. This will provide the clinician enough basis for a holistic treatment and management plan for the medically-ill patient that will definitely improve compliance to treatment and management; increase health and mental health literacy; maximize the use of health resources; and, provide a more humanized art of healing. 


\section{Acknowledgments}

Philippine Council for Health Research and Development (PCHRD) for supporting this study in part.

\section{References}

1. Creed F. Assessing depression in the context of physical illness. In: Robertson MM, Katona CLE, eds. Perspectives in Psychiatry: Depression and Physical Illness. Volume 3. Crichester: John Wiley \& Sons; 1997. pp. 3-7.

2. Maguire P, Hopwood P, Tarrier N, Howell T. Treatment of depression in cancer patients. Acta Psychiatr Scand Suppl. 1985; 320:81-4.

3. Speigel D. The effects of psychosocial interventions on cancer survival. In: Hall N, Altman F, Blumenthal S, eds. Mind-body Interactions and Disease and Psychoneuroimmunological Aspects of Health and Disease. Washington, DC: Health Dateline Pres; 1996. pp. 275-281.

4. Andreoli PB, Citero Vde A, Mari Jde J. A systematic review of studies of the cost-effectiveness of mental health consultation-liaison interventions in general hospitals. Psychosomatics. 2003; 44(6):499-507.

5. Hopwood P, Howell A, Maguire P. Psychiatric morbidity in patients with advanced cancer of the breast: Prevalence measured by two selfrating questionnaires. Br J Cancer. 1991; 64(2):349-52.

6. Meakin CJ. Screening for depression in the medically ill, the future of paper and pencil tests. Br J Psychiatry. 1992; 160:212-6.

7. Goldberg D. The Detection of Psychiatric Illness by Questionnaire, Psychol Med. 1979; 9:139-45.

8. Zung WW K. A Self-Rating Depression Scale. Arch Gen Psychiatry. $1965 ; 12: 63-70$
9. Beck AT, Ward CH, Mendelson M, Mock J, Erbaugh J. An inventory for measuring depression. Arch Gen Psychiatry. 1961; 4:561-71.

10. Zigmond AS, Snaith RP. The hospital anxiety and depression scale. Acta Psychiatr Scand. 1983; 67(6):361-70.

11. Herrmann C. International experiences with the Hospital Anxiety and Depression Scale - A review of validation data and clinical results. J Psychosom Res. 1997; 42(1):17-41.

12. Hsiao JK, Bartko JJ, Potter WZ Diagnosing diagnoses, Receiver operating characteristic methods and psychiatry. Arch Gen Psychiatry. 1989; 46(7):664-7.

13. Goldberg DP, Cooper B, Eastwood MR, Kedward HB, Shepherd M. A standardized psychiatric interview for use in community surveys. Br J Prev Soc Med. 1970; 24(1):18-23.

14. Baldessarini RJ, Finklestein S, Arana GW. The predictive power of diagnostic tests and the effect of prevalence of illness. Arch Gen Psychiatry. 1983; 40(5):569-73.

15. Murphy JM, Berwick DM, Weinstein MC, Borus JF, Budman $\mathrm{SH}_{,}$ Klerman GL. Performance of screening and diagnostic tests: Application of receiver operating characteristic analysis. Arch Gen Psychiatry. 1987; 44(6):550-5.

16. Mayou R, Hawton K. Psychiatric disorder in the general hospital. Br J Psychiatry. 1986; 149:172-90.

17. Perlas $\mathrm{AO}$, Querijero $\mathrm{MB}$, Abcede $\mathrm{DA}$, et al. The prevalence of psychiatric disorders among the chronically-ill medical patients in selected tertiary hospitals in the Philippines. Philipp J Psych. 2004; 28(1):7-24.

18. Flint AJ, Rifat SL. Factor Structure of the Hospital Anxiety and Depression Scale in Older Patients with Major Depression. Int J Geriatr Psychiatry. 2002; 17(2):117-23.

19. Roberston M, Katona C., ed., Depression and Physical illness, John Wiley \& Sons, 1997

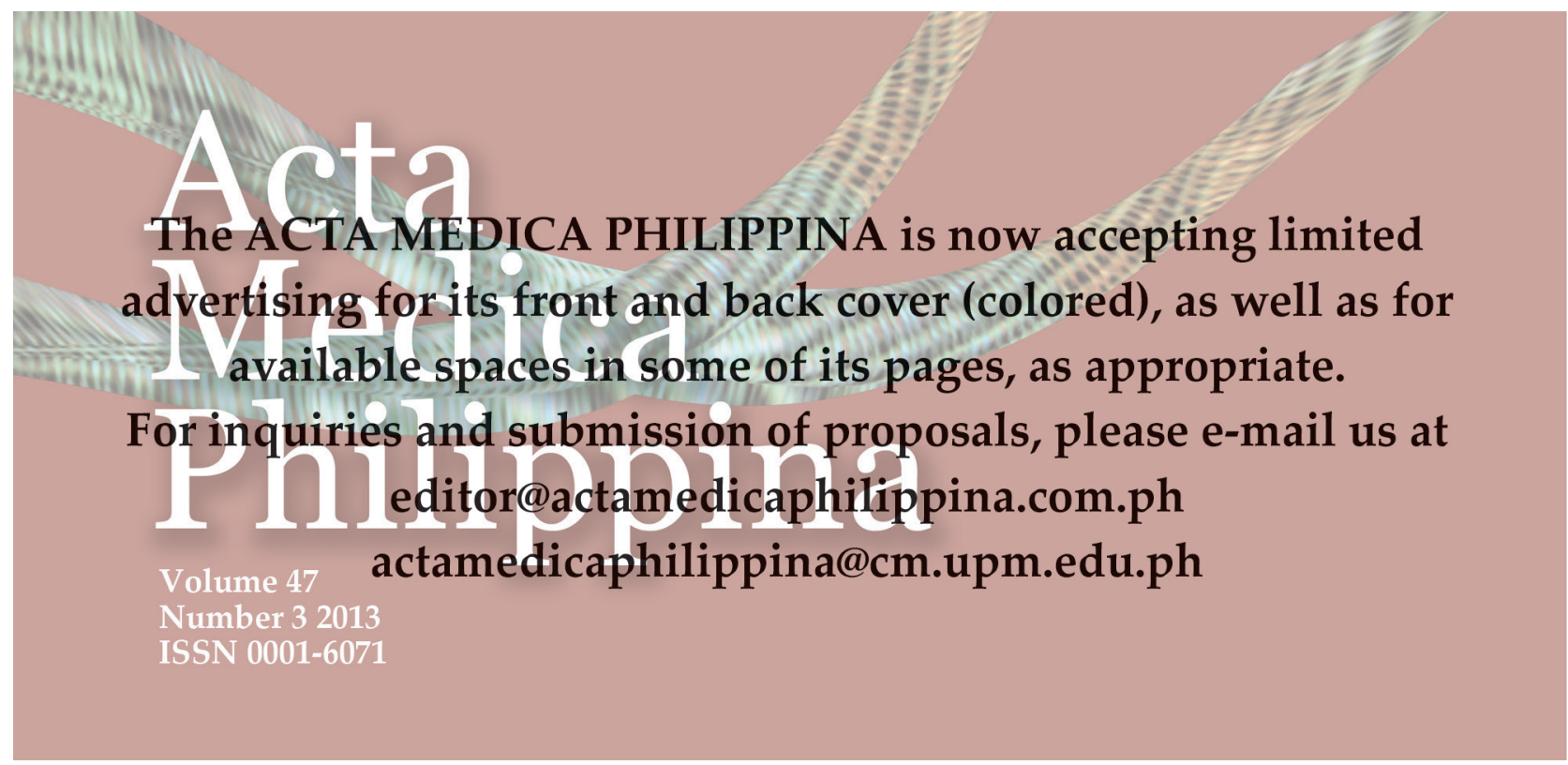

